\title{
Algebraic Approach to Modeling the Management Systems of the Sixth Technological Mode
}

\section{Yury B. Melnikov¹, Alexandr V. Staradanov², and Anna V. Lapteva ${ }^{1}$}

${ }^{1}$ Institute of Management and Information Technology, Ural State University of Economics, Yekaterinburg, Russian Federation

${ }^{2}$ Institute of Radio Electronics and Information Technologies - RTF, Ural Federal University named after the first President of Russia B. N. Yeltsin, Yekaterinburg, Russian Federation

\section{Abstract}

The aim of this research is to highlight the issues of building the models of control for automotion of the control process and, in particular, by using the artificial intelligence. The urgency of the problem is due to the passage of the economy from the fifth technological mode to the sixth one [1-5]. This passage is accompanied by the use of very complex automatic control systems, which are not limited only by automation

Corresponding Author:

Yury B. Melnikov

UriiMelnikov58@gmail.com

Published: 21 January 2021

Publishing services provided by Knowledge E

(c) Yury B. Melnikov et al. This article is distributed under the terms of the Creative Commons Attribution License, which permits unrestricted use and redistribution provided that the original author and source are credited.

Selection and Peer-review under the responsibility of the XXIII International Conference Conference Committee. of the executed algorithms. Management automation requires formalization of this process, construction and use of various management models. The latter requires the formalization and use of various management models that reflect various aspects of the management system. For simultaneous application of several fundamentally different models, an algebraic approach to modeling is proposed, which consists in distinguishing the following three components: 1) system of the basic models; 2) systems of standard transformations and standard combinations of models; 3) approximation mechanism intended to an approximate representation of the required model as the result of typical transformations and typical combinations of the basic models. The process plan is considered as the main activity model, we consider the strategy as the mechanism for creating the plan. Two ways of describing a strategy are proposed: a hierarchical model and an algebraic representation of a strategy. The study is a theoretical one. The methodological basis is the system analysis (A.A. Bogdanov) and the theory of modeling by Yu.B. Melnikov, in particular, the theory of adequacy, the theory of strategies, etc.

Keywords: management model, algebraic approach to modeling, strategy of activity, purpose of activity.

\section{Introduction}

A number of scientists believe that the world is moving from the fifth technological order to the new sixth one [6-8]. For example, according to S.Yu. Glazyev [7], you can get out 
should be done as quickly as possible. Latecomers to go to a new mode, they will be doomed to remain backward appendages of countries that have switched to the sixth techno-warehouse in time. It is acceptable that countries that have not completed the fifth technological mode have a chance to jump to the sixth techno-laying. Therefore, a large number of studies are currently being conducted on various aspects of the passage to a new technological structure.

\section{Materials and Methods}

The study has a theoretical character. The methodological basis is the system analysis (A.A. Bogdanov) and the theory of modeling by Yu.B. Melnikov, in particular, the theory of adequacy, the theory of strategies, etc.

\section{Results and Discussion}

Some experts believe that the essence of the sixth technological mode is the development and implementation of:

1. new quantum technologies, i.e., quantum computer, quantum cryptography, and quantum teleportation;

2. technologies for new clean energy;

3. nanotechnology in everyday life, mechanical engineering, construction, medicine, and biology; mainly in the form of new materials;

4. new types of vehicles and their combinations in the system;

5. smart home technologies;

6. robots with elements of artificial intelligence, and android robots.

One of the features of the sixth economy mode is the change in the process control system. Man is often not can directly manage nano-objects, and complex transport systems. Artificial intelligence can consider one of the options for automating the mental activity. Automation and mechanization of activities in the history of mankind have passed a number of stages such as:

1. creation of tools to compensate the imperfections of the body (a club as compensation for insufficient strength of predator limbs, a knife as compensation of insufficient tooth size and jaw strength, etc.); 
2. increase in power supply and the efficiency of physical labor through creation of new engines and propulsors (use of water and wind forces, steam forces, use of internal combustion engines, electricity, creation propellers in the form of a screw, wheel, etc.);

3. physical labor automation;

4. execution automation of the algorithms in mental work (arithmometers, computers for calculations);

5. intellectual work automation (including artificial intelligence).

Thus, technological progress is characterized, in particular, by a gradual passage from physical automation activities to automate intellectual activity. The passage to the sixth mode of the economy is largely connected with the passage from automation of algorithmic activities to activities with a more complex control system. Management automation requires formalization of this process, construction and use of different control models.

Traditionally, the management issues are considered in the management theory and mathematical control theory. But in theory, management usually refers to the management of people and groups of people, and the mathematical theory of management is a field of mathematics. Therefore, within the framework of this theory, they usually work with already formalized models, moreover, as a rule, these models are systems of differential or difference equations. We are interested in formalization of various control models in this research. These models should reflect various aspects of the management system: work with information (collection, processing, generation of information, its evaluation, use, etc.), formation, implementation and adjustment of management decisions, formation of motivation, etc.

To create management systems that are adequate to the needs of a society in passage from the fifth economic structure to the sixth structure, complex models (including computer ones) are required that reflect various aspects of the management process. In order to create such models, we propose applying the algebraic approach to modeling, which is a system of three components [9]:

1. system of the basic models;

2. a system of type transformations and type combinations of models;

3. an approximation mechanism designed to (generally speaking, approximate) represent the required model as the result of applying the standard model transformations and typical combinations of the basic models. 
For example, in contemporary radio electronics, the models of radio components, microcircuits, expansion cards (video cards, sound cards, etc.) act as the basic elements.

Typical conversions and typical combinations consist of methods for connecting the radio components and assemblies (soldering, using standard connectors and interfaces, etc.), methods for replacing and combining parts and assemblies, and others. The approximation mechanism includes: lists of compatible equipment, typical solutions for radio circuits and components, methods for calculating electronic circuits, technical reference manuals for components and parts, $C A D$, simulation programs, etc.

In this research, we will focus on the plan of activities as one of the most popular management models in practice. The creator of the plan (for example, some computer system, say, a knowledge base) and the executor of the plan (for example, the robot control system) perceive each item in the plan either as a link to some algorithm of actions, or as a link to the (local) goal of the activity. Now, we restrict ourselves to modelling the construction of the plan.

As a planning and purpose-setting tool, we propose using activity strategies, see Figure 1. The interpretation presented in Figure 1 is consistent with the interpretation of this concept in the engineering [10], Political Science [11], Economics [12-14].

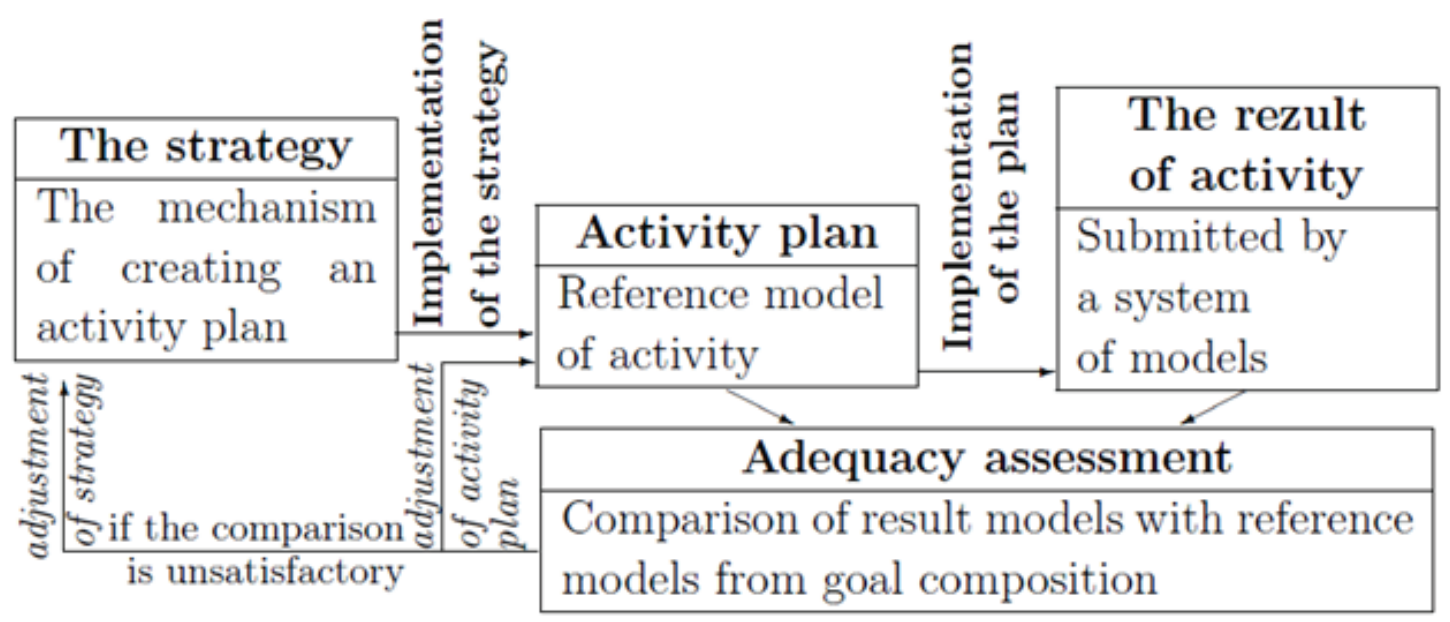

Figure 1: Strategy and its implementation

Today we consider the deductive assignment of the concept of "strategy" (using the definition) inappropriate due to the versatility and diversity of this concept (it includes managerial, economic, social, and other aspects). Therefore, at present, to formalize the concept of "strategy of activity," we consider the inductive approach to be preferable, which consists, in this case, of constructing a system of strategy models that reflect its various aspects. In this paper, we will be guided by our model, which we called hierarchical, see Figure 2. 


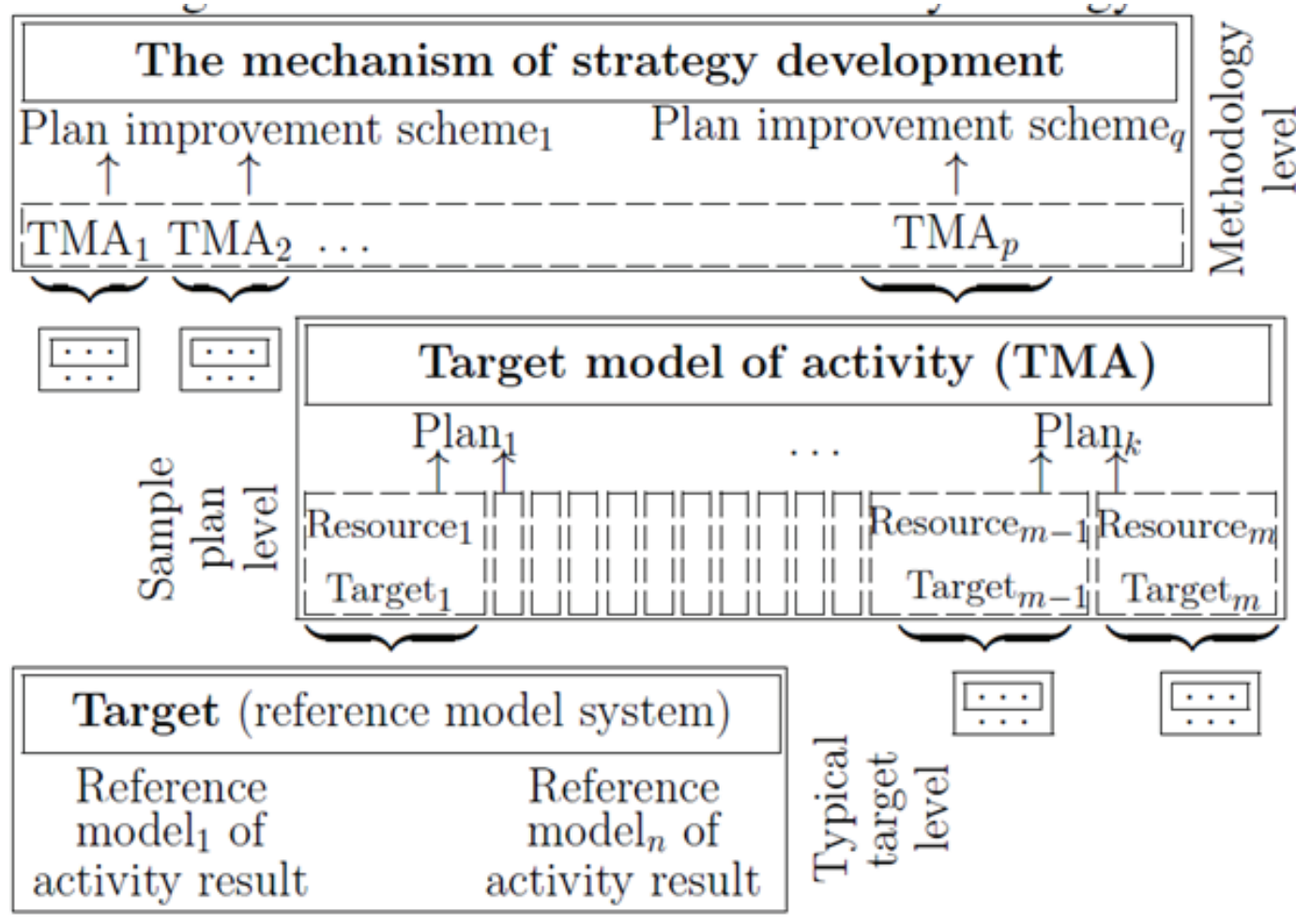

Figure 2: Hierarchical model of activity strategy

The lower level of the strategy (the level of typical purposes) constitutes a system of purposes typical for the given type of activity. For example, for geometry, the typical is the purpose represented by the requirement "find the area of the triangle", and the purpose of "find the green triangle" is not typical. According to the GOST 34.003-90, the purpose of the activity is the desired result of the activity process. The philosophical encyclopedia gives the following interpretation of this concept: "The purpose is one of the elements of human behavior and conscious activity, which characterizes the anticipation in thinking the result of activity and the way of its implementation using certain means. The purpose is a way to integrate various actions." In our opinion, all of these interpretations of the concept of "purpose of activity" are not entirely consistent. For example, the subject of activity can anticipate the negative or undesirable consequences of the activity. But this does not mean that these expected consequences are also part of the purpose. In addition, the phrases "desired results" and "element of behavior", etc., in our opinion, are not constructive enough as generic concepts. For example, using these concepts is not easy to construct criteria for assessing the correct understanding the performer of the purpose set before him.

To build a constructive interpretation of the concept of "purpose of activity", we proposed to consider the concept of purpose not as a "starting point" for building a plan, but as a means of determining the "final point" for fulfilling a plan, see Figure 1. In 
order to find out whether the purpose of an activity has been achieved, it is necessary to compare the achieved result with some reference models. Therefore, we will interpret purpose of activity as a system of reference models of the result of activity.

For example, the purpose of "find a triangle" includes reference models defined by the phrases "triangle with sides of length (lengths of three sides are indicated)", "triangle with sides (lengths of two sides are indicated) and the angle between them (angle value is indicated)", "triangle with a side (its length is indicated) and corners adjacent to it (the values of two angles are indicated)", "triangle that is a section of such a body (the body is described and how the section is drawn)", "triangle that is the face (projection) of such a polyhedron", "triangle for which spots (described) its construction algorithm", "triangle, which is the intersection (union, etc.) of some figures", "triangle, in which the described arrangement of vertices and / or sides", et al.

The richer the composition of the purpose, that is, the more diverse are the reference models in the composition of the purpose, usually easier to build a plan to achieve this purpose. In order to ensure the completeness of the purpose composition, it is useful to have different classifications of reference models as part of this purpose. We usually use three classifications. In the first, reference models are divided into three classes:

1. the language of the model;

2. templates;

3. specific samples of the activity result.

In another classification, reference models are divided into external and internal ones. Internal task of the model describes the model through its elements and characteristics. The example defines a triangle using its sides and angles refers to the internal definition of the model. External task of the model consists of its description using objects external to it. For example, the external task of a triangle refers to its representation in the form of a face or section of a polyhedron, in the form of a geometric shapes intersection or combination, or as the inside of a closed three-link polyline. The third classification is based on a direct and indirect specification of the model. We are talking about a direct model assignment when its elements, characteristics and relationships are explicitly described. The example defines a triangle by describing the location of its vertices and / or sides. Indirect model assignment is distinguished by a description of the characteristic properties of this model or its elements, i.e. a description of such properties that determine the model to the equality of objects. For example, defining a triangle using the lengths of its sides is indirect. Since, firstly, the triangle is uniquely 
defined (up to the geometric equality of the figures) using the lengths of its three sides, and, secondly, the segment is also determined by its length uniquely in the same sense of equality of figures.

The next level of the hierarchical strategy model is the level of model plans, see Figure 2, that we call the purpose activity model (TMA). In the framework of the TMA, the purpose of activity is compared with the set of resources of a certain standard plan for achieving this purpose using these resources. We will call TMA the full purpose activity model if the plan, firstly, requires the resources available to the plan executor. Secondly, he perceives all the plan items either as a reference to a known algorithm, or as a purpose for which the executor several algorithms for its achievement are known, and for at least one of these algorithms, the contractor has the resources necessary for its implementation.

An example of an element from TMA is the purpose represented by the phrase "geometrically interpret the distance between the figures". This corresponds to the standard plan "draw a segment whose length, by definition, coincides with the specified distance". The role of the resource is to determine the distance between these figures. It also can be a typical algorithm for conducting the corresponding segment, information about the figures, the distances between which are in question, and so on.

In the case when the purpose activity model is not complete, modification of the standard plan is required to the state where the resulting TMA becomes complete. To do this, the top level of the strategy (the methodology level) is connected, which we call the strategy development mechanism, see Figure 2.

Examples of elements of the strategy development mechanism are the method of mathematical induction, the method of reasoning "from the contrary", analytical [15] (see Figure 4) and synthetic (see Figure 5) methods for finding a solution, etc.

Consider the strategy of solving the geometric tasks about finding the geometric values. In the process of constructing this strategy, it turned out that the geometric drawing in itself is not a model of the text of the geometric task, see Figure 3.

The solution, in which the equation $B C A K=A C B M$ is obtained by calculating twice the double area of the triangle $A B C$, is based on the model consisting of the following figures: segments $A C, B C, A K, B M$ and the triangle $A B C$, see Figure $3 a$. Another solution based on the similarity of the triangles $A K C$ and $B M C$ uses a geometric model that considers the segments $A C, B C, A K, B M$ and triangles $A K C$ and $B M C$, see Figure $3 \mathrm{~b}$. The second solution will not change even after deleting the side $A B$, see Figure $3 c$, which is unacceptable for the first solution. Thus, according to the drawing and the condition of the problem, you can build different geometric models. 


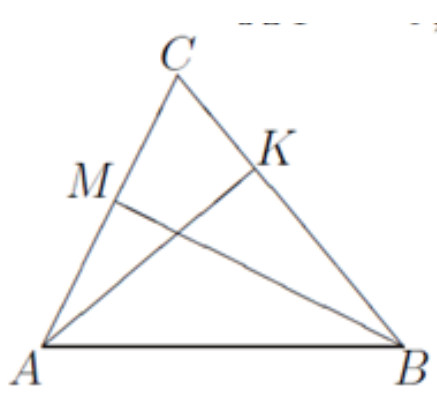

a

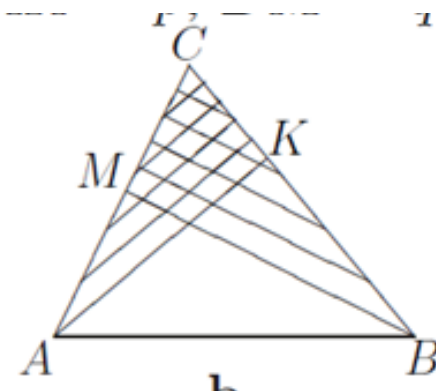

b

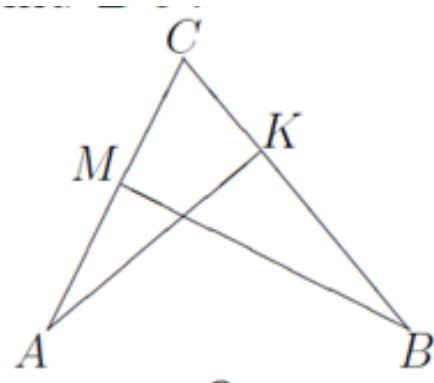

C

Figure 3: Geometric drawing is not a geometric model: $A C=b, A K=p, B M=q$. Find $B C$.

In order to apply the well-known analytic and synthetic methods in information systems, a more rigorous formalization of them is necessary. One of the formalization options is presented for the analytic method in Figure 4, and for the synthetic method, in Figure 5.

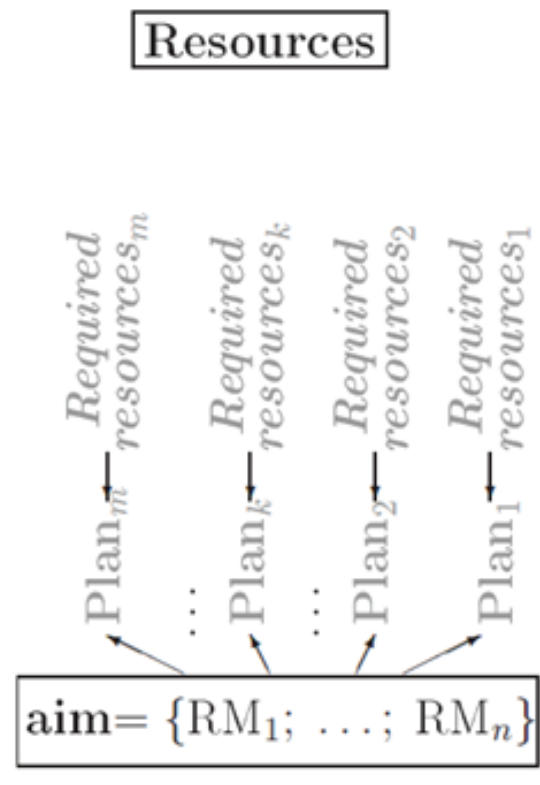

$-\mathrm{a}$

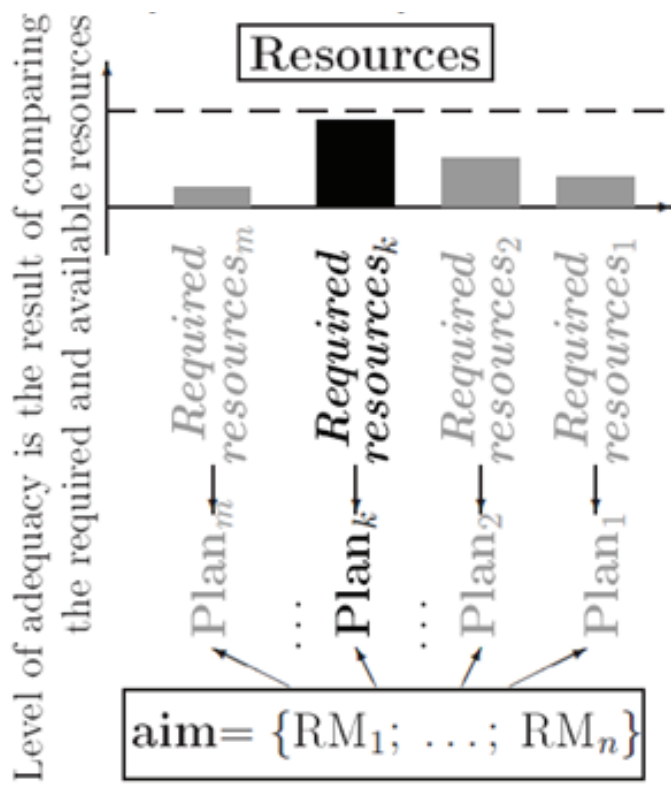

b

Figure 4: Illustration to the analytical analysis

Now, we will consider application of the strategy to solving geometric task using the example of the task "Inside a $60^{\circ}$ angle, there is a point $M$ at a distance of $\sqrt{7}$ and $2 \sqrt{7}$ from the sides of the corner. Find the distance from $M$ to the top of the corner."

Let us consider implementation of the strategy using the strategy development mechanism, see Figure2.

Firstly, we apply the analytical method. The objectives of "finding distance" correspond to two typical plans:

plan 1: 


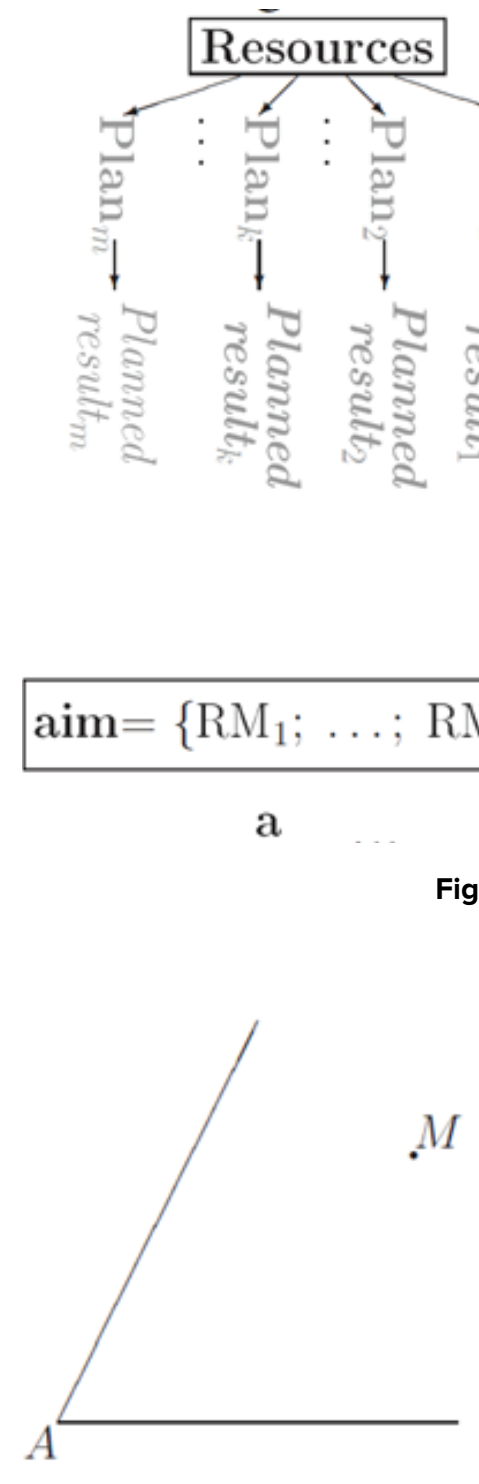

a

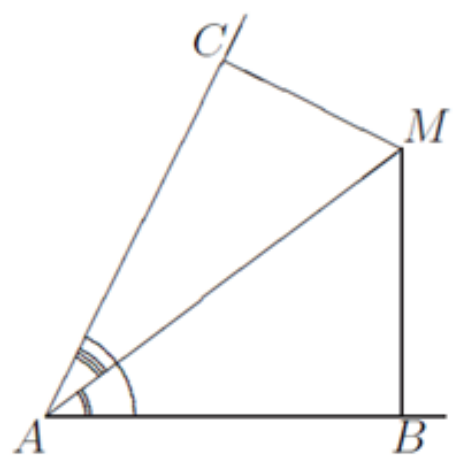

b

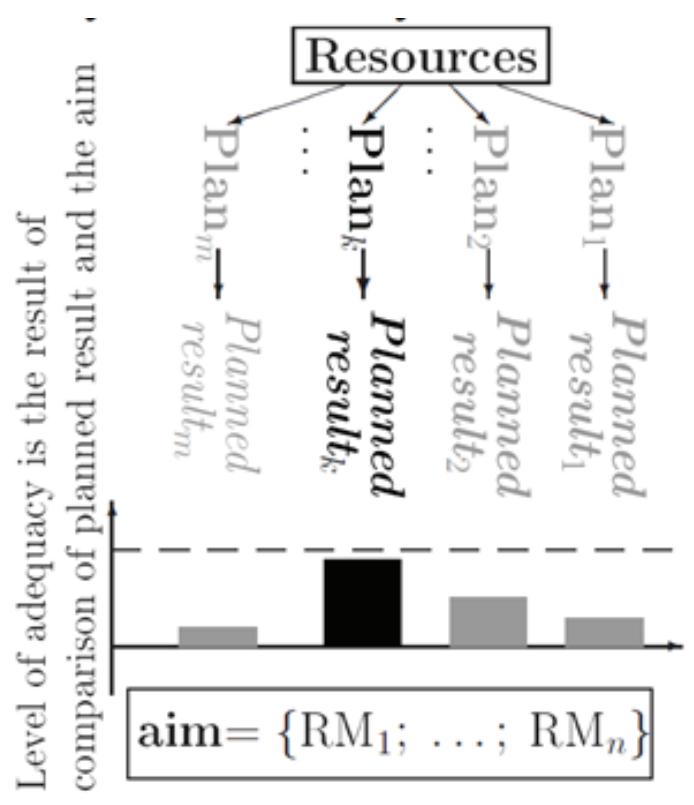

b

Figure 5: Illustration to the synthetic analysis

Figure 6: Illustration for an example of applying the strategy for solving the geometric task

1.1) select and apply the appropriate formula;

plan 2:

2.1) construct a segment whose length is by definition equal to the desired distance (i.e., AM);

2.2) find the length of the segment $A M$.

We do not have enough resources to complete the first plan (there is no necessary formula).

To fulfill the second plan, we will construct the segment $A M$ in Figure 6a. To calculate the length of a segment, the resource is geometric shapes, for which $A M$ is the side, 
radius, and others. Now the secondary target is represented by section 2.2 . There are conditions for applying the synthetic method.

The condition of the problem gives the resource in the form of distances from $M$ to the sides of the corner; there are several typical plans for using this resource:

plan 2.2.1:

2.2.1.1) substitute these distances into some formula;

plan 2.2.2:

2.2.2.1) draw segments $C M, B M$;

2.2.2.2) highlight the figures in the drawing, allowing to express the desired value through the known;

plan 2.2.3:

2.2.3.1) draw segments $C M, B M$;

2.2.3.2) enter a symbolic identifier for the desired value (for example, $A M$ );

2.2.3.3) highlight the figures in the drawing that allows you to calculate a certain value in two ways (i.e., get the equation);

2.2.3.4) get the equation for $A M$;

2.2.3.5) solve the equation for $A M$;

2.2.3.6) geometrically interpret the result (for example, remove "extraneous roots"); plan 2.2.4:

2.2.4.1) draw segments $C M, B M$;

2.2.4.2) enter a symbolic identifier for the desired value (for example, $A M$ );

2.2.4.3) find configurations on the drawing that allows you to build geometric shapes that are important for calculating the length $A M$;

2.2.4.4) calculate a certain value in two ways (i.e., get an equation);

2.2.4.5) get the equation by calculating the value of some geometric quantity in two ways;

2.2.4.6) solve the equation with respect to $A M$;

2.2.4.7) geometrically interpret the result (for example, remove "extraneous roots").

Plans 2.1 and plans 2.2 were not implemented.

The result of the implementation of sections 2.2.3.1-2.2.3.4 is Figure $6 \mathrm{~b}$ and the equation $\arcsin (\operatorname{sqrt7} / A M)+\arcsin (2 \sqrt{7} / A M)=60^{\circ}$. The implementation of section 2.2.3.5 may cause difficulties for the student (although when using the strategy proposed by us, there should not be problems solving with sufficient knowledge of trigonometry). 
The result of the implementation of sections 2.2.4.1-2.2.4.5 is Figure $6 \mathrm{c}$ and the equation

$$
\frac{1}{2} \sqrt{7} \cdot 2 \sqrt{7} \sin 120^{\circ}=\frac{14 \cdot \sqrt{7+28-2 \cdot 14 \cos 120^{\circ}}}{2 \cdot A M}
$$

( $A M$ is the diameter of the circle circumscribed around the triangle $B C M$ ). The implementation of sections 2.2.4.6 and 2.2.4.7 usually does not cause problems.

As experience has shown, the task using the hierarchical model, see Figure 2, for complex strategies is impractical: excessively cumbersome and inapplicable in practice. An alternative is the algebraic representation of strategies. In particular, we obtained the algebraic expansions for the strategies of routine research [9] and routine design activities, as well as strategies for routine modeling. All these activities are axiomatically determined by us.

\section{Conclusions}

1) The formalizations of the concepts "purpose of activity" and "strategy of activity" that we have proposed, combined with an algebraic approach to building strategies and other models, are used by us to organize the process of teaching mathematics at the Ural State University of Economics. These formalizations can be used to create control systems based not only on the implementation of algorithms, but, also, on the implementation of strategies.

In particular, the strategy for solving the geometric "computing" tasks in combination with models for implementing this strategy (see Figure 1) can be used as a component of a decision support system and even as a component of an automatic decision search system.

2) Formalization of purposes typical for a certain field of activity is a non-trivial task for a specialist in this field. The value of this work for a computerized control system is very high. As experience has shown, our proposed classifications of reference models (as part of the purpose) significantly facilitate the process of formalizing the purpose.

3) The implementation of the algebraic approach to the presentation of complex strategies allows you to change the management process. For example, in the process of studying new material, organized as training in the implementation of strategies, students accumulate experience in independent research and project activities, master the necessary apparatus (experience in implementing basic strategies) and skills. 


\section{References}

[1] Silin, Ya. P., Animitsa, Ye. G. and Novikova, N. V. (2016). New Normal in Russian Economy: Regional Specificity. Ekonomika Regional Economy of Region, vol. 12, issue 3 , pp. 714-725.

[2] Pukharenko, Y. V., Norina N. V. and Norin, V. A. (2017). Russian engineering education in the era of change. European Journal of Engineering Education, vol. 42, issue 2, pp. 171-187.

[3] Voronin, V. (2017). Cognitive sciences and education. INTED2017: 11th International technology, education and development conference. Ed. by Chova, LG and Martinez, AL and Torres, IC. INTED Proceedings. Lauri Volpi 6, Valenica, Burjassot 46100, Spain: lated-int assoc technology education \& Development. 11th International Conference on Technology, Education and Development (INTED), Valencia, Spain, pp. 5326-5332.

[4] Silin, Y. P., Animistra, Y. G. and Novikova, N. V. (2017). Trends in the Development of the Ural Macroregion's Economic Space. Upravlenets-The Manager, vol. 2, pp. 2-11.

[5] Stremousova, E. and Buchinskaia, O. (2018). Socio-economic contradictions of the sixth technological mode. 12th international days of statistics and economics. In T. Loster and T. Pavelka, (Eds.). Univ Econ, Dept Stat \& Probabil; Univ Econ, Dept Microecon; Tech Univ Kosice, Fac Econ; Ton Duc Thang Univ; Univ Econ, Fac Business Adm; Univ Econ, Fac Informat \& Stat. Fugnerova 691, Slany, 27401, Czech Republic: Melandrium, 12th International Days of Statistics and Economics, Prague, Czech Republic, pp. 1708-1717.

[6] Bodrunov, S. D. (2018). From ZOO to NOO: Man, Society and Production in the Conditions of a New Technological Revolution. Voprosy filosofii, vol. 7, pp. 109-118.

[7] Uskov, V. S. (2019). Russian Industrial Sector Development in the Context of New Technological Revolution. Economic and social changes-facts trends forecast, vol. 12 , issue 2 , pp. 128-146.

[8] Idrisov, G. I., Knyaginin, V. N., Kudrin, A. L. and Rozhkova, E. S. (2018). New technological revolution: Challenges and opportunities for Russia. Voprosy ekonomiki, vol. 4, pp. 5-25.

[9] Melnikov, Yu. B., Onokhina, E. A., and Shitikov, S. A. (2016). The algebraic presentation of research strategy in the activity of tax authorities. Globalization and its socioeconomic consequences. 16th International Scientific Conference. Proceedings. Part III. 5th-6th October 2016. Rajecke Teplice, Slovak Republic. ZU-University of Zilina. Georg, Bajzova 11, 01001 Zilina, Slovak Republic, pp. 1355-1362. 
[10] Ali, M., Adnan, M. and Tariq, M. (2019). Optimum control strategies for short term load forecasting in smart grids. International journal of electrical power \& Energy systems, vol. 113, pp. 792-806.

[11] Lena, D. A. and Hetzer, A. (2019). The inferiority of the other. Strategies of delegitimization of Latin American politics in the German media discourse. Chasquirevista latinoamericana de comunicacion, vol. 139, pp. 75-94.

[12] Pekcan, R. (2019). Turkey's trade strategies in the new digital age. Turkish policy quarterly, vol. 17, issue 4, pp. 15-22.

[13] Buckles, K. (2019). Fixing the Leaky Pipeline: Strategies for Making Economics Work for Women at Every Stage. Journal of economic perspectives, vol. 33, issue 1, pp. $43-60$.

[14] Gui, L., Tang, C. S. and Yin, S. (2019). Improving Microretailer and Consumer Welfare in Developing Economies: Replenishment Strategies and Market Entries. M \& Sommanufacturing \& Service operations management, vol. 21, issue 1, pp. 231-250.

[15] Finger, M. (2010). Analytic Methods for the Logic of Proofs. Journal of logic and computation, vol. 20, issue 1, pp. 167-188. 16th International Conference on Automated Reasoning with Analytic Tableaux and Related Methods, Aix en Provence, France, Jul 03-06, 2007. 